\title{
Does Early versus Delayed Spanning External Fixation Impact Complication Rates for High-energy Tibial Plateau and Plafond Fractures?
}

\author{
Justin M. Haller MD, David Holt MD, David L. Rothberg MD, \\ Erik N. Kubiak MD, Thomas F. Higgins MD
}

Published online: 19 October 2015

(C) The Association of Bone and Joint Surgeons( 2015

\begin{abstract}
Background High-energy tibial plateau and tibial plafond fractures have a high complication rate and are frequently treated with a staged approach of spanning external fixation followed by definitive internal fixation after resolution of
\end{abstract}

One of the authors (ENK) has received research support funding from the Department of Defense Congressionally Directed Medical Research Program and VA Early Feasibility Program. One of the authors (TFH) lists the following relevant financial activities outside of this work and/or any other relationships or activities that readers could perceive to have influenced, or that give the appearance of potentially influencing, this manuscript: DePuy Synthes (West Chester, PA, USA) in the amount of less than USD 10,000. One of the authors (ENK) lists the following relevant financial activities outside of this work and/or any other relationships or activities that readers could perceive to have influenced, or that give the appearance of potentially influencing, this manuscript: CoNextions (Sandy, UT, USA) in the amount of more than USD 10,000, OrthoGrid (Salt Lake City, UT, USA) in the amount of more than USD 10,000, Zimmer (Warsaw, IN, USA) in the amount of more than USD 10,000, DePuy (Warsaw, IN, USA) in the amount of more than USD 10,000, and DJO (Vista, CA, USA) in the amount of less than USD 10,000. All ICMJE Conflict of Interest Forms for authors and Clinical Orthopaedics and Related Research $\mathbb{R}$ editors and board members are on file with the publication and can be viewed on request.

Each author certifies that his or her institution approved the human protocol for this investigation, that all investigations were conducted in conformity with ethical principles of research, and that informed consent for participation in the study was obtained.

J. M. Haller, D. Holt, D. L. Rothberg, E. N. Kubiak,

T. F. Higgins $(\bowtie)$

Department of Orthopaedics, University Orthopaedic Center, University of Utah, 590 Wakara Way, Salt Lake City, UT 84108, USA

e-mail: Thomas.higgins@hsc.utah.edu soft tissue swelling. A theoretical advantage to early spanning external fixation is that earlier fracture stabilization could prevent further soft tissue damage and potentially reduce the occurrence of subsequent infection. However, the relative urgency of applying the external fixator after injury is unknown, and whether delay in this intervention is correlated to subsequent treatment complications has not been examined.

Questions/purposes Is delay of more than 12 hours to spanning external fixation of high-energy tibial plateau and plafond fractures associated with increased (1) infection risk; (2) compartment syndrome risk; and (3) time to definitive fixation, length of hospitalization, or risk of secondary surgeries? We further stratified our results based on injury site: plateau and plafond. In practical clinical terms, many of these high-energy C-type articular fractures will arrive at the regional trauma center in the evening and this investigation attempted to explore if these injuries need to be placed in temporizing fixators that evening or if they may be safely addressed in a dedicated trauma room the next morning.

Methods We performed a retrospective review of all patients at a Level I university trauma center with highenergy tibial plateau and plafond fractures who underwent staged treatment with a spanning external fixation followed by subsequent definitive internal fixation between 2006 and 2012. Patients who received a fixator within 12 hours of recorded injury time were classified as early external fixation; those who received a fixator greater than 12 hours from injury were classified as delayed external fixation. There were 80 patients (42 plateaus and 38 plafonds) in the early external fixation cohort and 79 patients (45 plateaus and 34 plafonds) in the delayed external fixation cohort. Deep infection rate was $13 \%$ in plateau fractures and $18 \%$ in plafond fractures. Rates of infection, compartment 
syndrome, secondary surgeries, time to definitive fixation, and length of hospitalization were recorded.

Results Controlling for differences in open fracture severity between groups, there was no difference in infection for plafond (early fixation: 12 of 38 [32\%]; delayed fixation: seven of 34 [21\%]; adjusted relative risk $=1.39[95 \%$ confidence interval $\{\mathrm{CI}\}, 0.45-4.31], \mathrm{p}=$ 0.573 ) and plateau (early fixation: eight of 42 [19\%]; delayed fixation: nine of 45 [20\%]; adjusted relative risk: 0.93 [95\% CI, 0.31-2.78], $\mathrm{p}=0.861$ ) groups. For compartment syndrome risk, there was no difference between early and delayed groups for plateau fractures (early fixation: six of 42 [14\%]; delayed fixation: three of 45 [7\%]; relative risk $=0.47[0.12-1.75], \mathrm{p}=0.304)$ and plafond fractures (early fixation: two of 38 [5\%]; delayed fixation: three of 34 [9\%]; relative risk $=1.67[0.30-9.44], p=$ 0.662). There was no difference for length of hospitalization for early ( $9 \pm 7$ days) versus delayed fixation $(9 \pm 6$ days) (mean difference $=0.24$ [95\% CI, -2.9 to 3.4], $\mathrm{p}=$ 0.878 ) for patients with plafond fracture. Similarly, there was no difference in length of hospitalization for early (10 \pm 6 days) versus delayed fixation ( $8 \pm 4$ days) (mean difference $=1.6[95 \% \mathrm{CI},-3.9$ to 0.7$], \mathrm{p}=0.170$ ) for patients with plateau fracture. Time to definitive fixation for plateau fractures in the early external fixation group was $8 \pm 6$ days compared with $11 \pm 7$ days for the delayed external fixation group (mean difference $=2.9[95 \% \mathrm{CI}$, 0.13-5.7], $\mathrm{p}=0.040$ ); there was no difference in time to definitive fixation for early ( $12 \pm 7$ days) versus delayed (12 \pm 6 days) for patients with plafond fractures (mean difference $=0.39[95 \% \mathrm{CI},-2.7$ to 3.4], $\mathrm{p}=0.801$ ). There was no difference in risk of secondary surgeries between early external fixation (21 of 38 [55\%]) and delayed external fixation (13 if 34 [38\%]) for plafond fractures (adjusted relative risk $=0.69[95 \% \mathrm{CI}, 0.41-1.16], \mathrm{p}=$ $0.165)$ and no difference between early fixation (24 of 42 [57\%]) and delayed fixation (26 of 45 [58\%]) for plateau fractures (adjusted relative risk $=1.0$ [95\% CI, 0.70-1.45], $\mathrm{p}=1.00)$.

Conclusions We were unable to detect a difference in infection, compartment syndrome, secondary procedures, or length of hospitalization for patients who undergo early versus delayed external fixation for high-energy tibial plateau or plafond fractures. This may affect decisions for resource use at trauma centers such as whether high-energy periarticular lower extremity fractures need to be spanned on the evening of presentation or whether this procedure may wait until the morning trauma room. Given the high complication rate of these injuries and clinical relevance of this question, this may also need to be examined in a prospective manner.

Level of Evidence Level IV, therapeutic study.

\section{Introduction}

High-energy articular fractures of the tibial plateau and tibial plafond can be devastating injuries. Early morbidity of these injuries tends to be related to the extent of the soft tissue injury and potential for subsequent infection. With historical rates of infection after early definitive fixation for these injuries approaching 50\% in some series, a staged protocol with early external fixation followed by delayed definitive internal fixation has been widely adopted $[7,13,16]$. Despite this treatment algorithm, wound complications persist, and deep infection rates are reported to be between 5\% and $24 \%$ [2, 4-6, 12]. Given this high complication rate and the increased focus on resource utilization, identifying the ideal timing of surgical intervention for spanning external fixation is clinically significant. With the advent of dedicated daytime orthopaedic trauma operating rooms, nonemergent cases that arrive at night may often be scheduled for the trauma room the subsequent day. This may lead to improved resource use and improved clinical outcomes, especially considering that after-hours surgeries have been associated with higher rates of complications [10].

Temporizing external fixation for lower extremity periarticular fractures is a common surgery in which the degree of urgency or ideal timing of surgery has not previously been examined. To date, there are no studies comparing patient outcomes in early versus delayed external fixation in the setting of high-energy lower extremity articular trauma. Critical to an improved resource use strategy is an understanding of which injuries truly necessitate emergent intervention and which may reasonably be deferred to the next morning. The purpose of this study is to retrospectively determine if the time from injury to temporizing external fixation of high-energy tibial plateau and tibial plafond fractures affects clinical complication rates.

\section{Study Questions}

Is delay of more than 12 hours to spanning external fixation of high-energy tibial plateau and plafond fractures associated with increased (1) infection risk; (2) compartment syndrome risk; and (3) time to definitive fixation, length of hospitalization, or risk of secondary surgeries? We further stratified our results based on injury site: plateau and plafond.

\section{Patients and Methods}

This is a retrospective case series collected at the University of Utah Health Sciences Center, a regional Level I 
trauma center between 2006 and 2012. After institutional review board approval, all eligible patients meeting inclusion criteria, including minimum 6 months clinical followup, were collected.

All patients $\geq 18$ years old with high-energy tibial plateau and plafond fractures requiring temporizing external fixation followed by subsequent definitive internal fixation were collected. The decision to treat an injury with temporizing external fixation was at the discretion of the on-call surgeon as was the timing of external fixator placement. Fractures were defined as high-energy based on mechanism of injury (motor vehicle accident, motorcycle accident, crush, etc) and the presence of substantial comminution, limb shortening, bicolumnar involvement, or metaphyseal-diaphyseal dissociation.

Patients were excluded if they had external fixation at another facility, had inadequate records to determine time of injury, or had less than 6 months of clinical followup after definitive internal fixation.

All tibial plateau fractures in the study were treated with a spanning external fixator consisting of two 5-mm halfpins placed anterior or anterolateral in the femoral diaphysis and two 5-mm half-pins in the anteromedial aspect of the tibial diaphysis. Plafond fractures were treated with a delta frame consisting of two 5-mm pins in the anteromedial tibia and a 5- or 6-mm calcaneal transfixation pin with fixation in the forefoot at the discretion of the operating surgeon. Patients with open fractures received appropriate antibiotic prophylaxis and underwent irrigation and débridement at the time of external fixation. Patients diagnosed with compartment syndrome underwent fourcompartment fasciotomy followed by subsequent irrigation and débridement procedures until definitive closure could be obtained with primary closure, skin graft, or muscle flap. Timing of return to the operating room for removal of the external fixator and subsequent definitive operative reduction and internal fixation (ORIF) were at the discretion of the attending surgeon. All patients were treated by one of five surgeons (TFH, ENK, DLR, TCB, FN) fellowshiptrained in orthopaedic trauma or foot and ankle surgery.

Patients received 24 hours of intravenous antibiotics after external fixation and 24 hours of intravenous antibiotics after definitive fixation. ROM exercises were started immediately after definitive fixation for tibial plateau fractures and after 2 weeks of splinting for tibial plafond fractures. Per trauma team protocol, patients with plateau fractures received 6 weeks of low-molecular-weight heparin subcutaneously, and patients with tibial plafond fractures did not receive antithrombotic therapy unless they reported a personal or family history of a thromboembolic event.

Planned followup for all patients was a minimum of 1 year, and minimum followup for inclusion in the study was
6 months. All patients followed up in the clinic of the attending physician from their definitive fixation. Advancement of ROM, strengthening, and weightbearing was dictated by the attending physician.

The primary outcome was infection. Infection was subclassified into superficial and deep infection. Superficial infection was defined as wound drainage necessitating oral antibiotic treatment and/or any purulence found superficial to the fascia. Deep infection was defined as purulence deep to the fascia or any wound requiring more than one débridement.

Secondary outcomes included rate of compartment syndrome, time to definitive fixation, length of hospitalization, and number of secondary surgeries. Compartment syndrome was defined as any patient who underwent operative four-compartment release. Protocol at our institution dictates neurovascular examinations every 2 hours and examinations every 4 hours documented by housestaff for 24 hours after spanning external fixation and 24 hours after definitive fixation. Time to definitive fixation was the number of days between initial external fixation and definitive ORIF. Length of hospitalization was defined as the total number of days a patient was admitted to the hospital for both external fixation and definitive fixation. Secondary surgeries were defined as any unplanned trips to the operating room for the same injury after definitive fixation.

\section{Statistical Analysis}

Pearson's chi-square test and Fisher's exact test were used for the categorical variables between the early external fixation and delayed external fixation groups including sex, tobacco use, number of patients with compartment syndrome, and number of secondary surgeries. A twotailed Student's t-test was used for continuous variables including age, length of hospitalization, and time to definitive fixation. A Mann-Whitney U test was performed for comparisons of nonparametric variables including Injury Severity Score. Using the Shapiro-Wilk test for normality, the groups were not in a normal distribution with regard to time from injury to external fixation. For this portion of analysis, the Mann-Whitney U test was used to determine if the early and delayed groups were significantly different. Linear regression modeling was used to compare infection rates between the early external fixation and delayed external fixation groups while controlling for open fracture. Linear regression modeling limits the confounding that might be present as a result of an open fracture when comparing patient outcomes between the two groups. A p value $<0.05$ was considered to be significant. 
Table 1. Patient demographics for tibial plateau fractures and tibial plafond fractures

\begin{tabular}{|c|c|c|c|}
\hline Parameter & Early external fixation $(n=42)$ & Delayed external fixation $(n=45)$ & $\mathrm{p}$ value \\
\hline \multicolumn{4}{|l|}{ Tibial plateau fractures } \\
\hline Age (years) & $42(\mathrm{SD} 11$, median 43, range $25-77)$ & 45 (SD 12, median 44, range $25-65)$ & 0.29 \\
\hline Male gender & $27(64 \%)$ & $28(62 \%)$ & 1.0 \\
\hline Diabetes & $3(7 \%)$ & $5(11 \%)$ & 0.72 \\
\hline Tobacco use & $10(24 \%)$ & $11(24 \%)$ & 1.0 \\
\hline Work-related & $1(2 \%)$ & $2(4 \%)$ & 1.0 \\
\hline Injury Severity Score & $8(\mathrm{SD} 4$, median 4 , range $4-27)$ & 7 (SD 7, median 5, range 4-21) & 0.23 \\
\hline \multicolumn{4}{|l|}{ Mechanism } \\
\hline MVC & $9(21 \%)$ & $6(13 \%)$ & \\
\hline MCC & $11(26 \%)$ & $10(22 \%)$ & \\
\hline Fall & $9(21 \%)$ & $12(26 \%)$ & \\
\hline Skiing & $5(12 \%)$ & $7(16 \%)$ & \\
\hline Pedestrian versus automobile & $4(10 \%)$ & $3(7 \%)$ & \\
\hline ATV/snowmobile & $2(5 \%)$ & $3(7 \%)$ & \\
\hline Other (crush, etc) & $2(5 \%)$ & $4(9 \%)$ & \\
\hline Parameter & Early external fixation $(\mathrm{n}=38)$ & Delayed external fixation $(n=34)$ & $\mathrm{p}$ value \\
\hline \multicolumn{4}{|l|}{ Tibial plafond fractures } \\
\hline Age (years) & 41 (SD 11, median 40, range $21-74)$ & $42(\mathrm{SD} 14$, median 44 , range $20-63)$ & 0.77 \\
\hline Male gender & $30(79 \%)$ & $26(77 \%)$ & 1.0 \\
\hline Diabetes & $3(8 \%)$ & $2(6 \%)$ & 1.0 \\
\hline Tobacco use & $7(18 \%)$ & $12(35 \%)$ & 0.12 \\
\hline Work-related & $10(26 \%)$ & $4(12 \%)$ & 0.14 \\
\hline Injury Severity Score & $8(\mathrm{SD} 8$, median 5 , range $4-27)$ & 8 (SD 6, median 4, range 4-34) & 0.86 \\
\hline \multicolumn{4}{|l|}{ Mechanism } \\
\hline MVC & $9(24 \%)$ & $3(9 \%)$ & \\
\hline $\mathrm{MCC}$ & $4(10 \%)$ & $4(12 \%)$ & \\
\hline Fall & $20(53 \%)$ & $25(73 \%)$ & \\
\hline ATV/snowmobile & $0(0 \%)$ & $1(3 \%)$ & \\
\hline Other (crush, etc) & $5(13 \%)$ & $1(3 \%)$ & \\
\hline
\end{tabular}

$\mathrm{MVC}=$ motor vehicle collision; $\mathrm{MCC}=$ motorcycle collision; $\mathrm{ATV}=$ all-terrain vehicle.

Patient demographics and injury mechanism were not different between groups. Further details are described in detail (Table 1).

Between 2006 and 2012, 254 high-energy articular lower extremity injuries (145 plateaus, 109 plafonds) were treated at our facility with provisional external fixation. Ninety-five patients were excluded from analysis. Twelve patients were excluded because they had placement of external fixation at another facility. Five patients were excluded for medical records insufficient to determine time of injury. An additional 78 patients were excluded as a result of followup of less than 6 months. Of these excluded patients, there were 30 patients with plafond fracture with mean age of 42 years $(\mathrm{p}=0.851)$ and $67 \%(20$ of 30$)$ male $(\mathrm{p}=0.488)$ and there were 48 patients with plateau fracture with mean age 45 years $(\mathrm{p}=0.472)$ and $65 \%$ male $(\mathrm{p}=$ $0.854)$. All patients underwent spanning external fixation followed by definitive fixation. The remaining 159 patients (87 plateaus and 72 plafonds) formed our study group.

The early external fixation cohort was comprised of 80 patients (42 plateaus and 38 plafonds) and the delayed external fixation cohort was comprised of 79 patients (45 plateaus and 34 plafonds). Mean time from injury to application of a spanning external fixator was 7.5 hours (range, 3-12 hours) in the plateau early external fixation cohort, which is significantly less than the mean time to external fixator in delayed external fixation cohort (24 hours; range, $13-50$ hours; $p<0.005)$. Similarly, the time to spanning external fixator was significantly different between the plafond early external fixation cohort (mean, 8 
Table 2. Fracture characteristics for tibial plateau fractures and tibial plafond fractures

\begin{tabular}{|c|c|c|c|}
\hline Fracture classification & Early external fixation $(n=42)$ & Delayed external fixation $(n=45)$ & $\mathrm{p}$ value \\
\hline \multicolumn{4}{|l|}{ Tibial plateau fractures } \\
\hline Schatzker classification & & & 0.71 \\
\hline II & $3(7 \%)$ & $4(9 \%)$ & \\
\hline IV & $5(12 \%)$ & $6(11 \%)$ & \\
\hline $\mathrm{V}$ & $4(10)$ & $4(9 \%)$ & \\
\hline VI & $30(71 \%)$ & $31(71 \%)$ & \\
\hline Open fracture & $8(19 \%)$ & $2(4 \%)$ & 0.045 \\
\hline Grade I & 0 & 0 & \\
\hline Grade II & 4 & 1 & \\
\hline Grade IIIA & 1 & 0 & \\
\hline Grade IIIB & 3 & 1 & \\
\hline Grade IIIC & 0 & 0 & \\
\hline Fracture classification & Early external fixation $(\mathrm{n}=38)$ & Delayed external fixation $(\mathrm{n}=34)$ & $\mathrm{p}$ value \\
\hline \multicolumn{4}{|l|}{ Tibial plafond fractures } \\
\hline Open fracture & $17(45 \%)$ & $7(21 \%)$ & 0.045 \\
\hline Grade I & 2 & 1 & \\
\hline Grade II & 8 & 3 & \\
\hline Grade IIIA & 3 & 1 & \\
\hline Grade IIIB & 3 & 2 & \\
\hline Grade IIIC & 1 & 0 & \\
\hline
\end{tabular}

hours; range, 4-12 hours) and the plafond delayed external fixation cohort (mean, 31 hours; range, 13-168 hours; $\mathrm{p}<0.005)$. Average followup was similar between the early (16.5 months; range, 6-68 months) and delayed (14 months; range, 6-70 months) groups $(\mathrm{p}=0.22)$. No patients had to return to the operating room for revision of external fixation before the time of their definitive fixation. Mean Injury Severity Scores were similar between the groups as well. There were 24 open tibial plafond fractures (33\%) and 10 open tibial plateau fractures $(11.5 \%)$ (Table 2). There were significantly more open plafond and plateau fractures in the early group for both tibial plateau fractures $(\mathrm{p}=0.045)$ and tibial plafond fractures $(\mathrm{p}=$ $0.045)$.

\section{Results}

Controlling for differences in open fracture severity between groups, there was no difference in infection for plafond (early fixation: 12 of 38 [32\%]; delayed fixation: seven of 34 [21\%]; adjusted relative risk [RR] $=1.39$ [95\% confidence interval $\{\mathrm{CI}\}, 0.45-4.31], \mathrm{p}=0.573$ ) and plateau (early fixation: eight of 42 (19\%); delayed fixation: nine of 45 (20\%); adjusted RR: 0.93 [95\% CI, 0.31-2.78], $\mathrm{p}=0.861)$ groups. Initial bivariate analysis revealed no differences in infection risk for plateau fractures between early and delayed groups $(\mathrm{RR}=1.05$ [95\% CI, 0.45-2.47], $\mathrm{p}=1.00)$. Seventeen combined deep and superficial infections $(19.5 \%)$ occurred in patients who sustained a tibial plateau fracture, 11 of which $(13 \%)$ were defined as deep and six as superficial (Table 3). Eight infections (five deep and three superficial) occurred in the early external fixation cohort and nine infections (six deep and three superficial) in the delayed external fixation cohort for plateau fracture. Eleven patients with deep infection underwent a total of 26 surgical débridements (two per patient) to eradicate the infection. Of the 10 patients with open fracture, two developed an infection (20\%). Similarly, there were no differences in infection risk for plafond fractures based on initial bivariate analysis $(R R=0.65$ [95\% CI, 0.29-1.46], $\mathrm{p}=0.442$ ). Nineteen deep or superficial infections $(26 \%)$ occurred in patients who sustained a tibial plafond fracture with 13 patients (18\%) developing deep infection (Table 3). There were 12 infections (nine deep and three superficial) in the early external fixation group and seven infections (four deep and three superficial) in the delayed external fixation group. Thirteen patients who developed deep infection underwent a total of 38 surgical débridements (three per patient). Of the 24 patients 
Table 3. Patient outcomes for tibial plateau fractures and tibial plafond fractures

\begin{tabular}{llll}
\hline Parameter & $\begin{array}{l}\text { Early external } \\
\text { fixation }(\mathrm{n}=42)\end{array}$ & $\begin{array}{l}\text { Delayed external } \\
\text { fixation }(\mathrm{n}=45)\end{array}$ & $\begin{array}{l}\text { Relative risk/mean } \\
\text { difference }(95 \% \mathrm{CI})\end{array}$ \\
\hline $\begin{array}{l}\text { Tibial plateau fractures } \\
\text { Infection }\end{array}$ & $8(19 \%)$ & $9(20 \%)$ & $0.93(0.31-2.78)$ \\
Compartment syndrome & $6(14 \%)$ & $3(7 \%)$ & $0.47(0.12-1.75)$ \\
Secondary procedures & 46 & 60 & $1.5(-3.9$ to 0.70$)$ \\
Length of hospitalization & 8 days $(3.8)$ & 10 days $(6.4)$ & $2.92(0.13-5.7)$ \\
Time to fixation & 8 days $(6.4)$ & 11 days $(6.7)$ & 0.304 \\
\hline Parameter & Early external & Delayed external & 0.586 \\
& fixation $(\mathrm{n}=38)$ & fixation $(\mathrm{n}=34)$ & 0.170 \\
\hline Tibial plafond fractures & & & 0.040 \\
Infection & $12(32 \%)$ & $7(21 \%)$ & $1.39(0.45-4.31)$ \\
Compartment syndrome & $2(5 \%)$ & $3(9 \%)$ & $1.67(0.30-9.44)$ \\
Secondary procedures & 56 & 29 & $0.24(-2.9$ to 3.4) \\
Length of hospitalization & 9 days $(7.2)$ & 9 days $(6.1)$ & $0.39(-2.7$ to 3.4) \\
Time to fixation & 12 days $(6.2)$ & 12 days $(6.8)$ & 0.573 \\
\hline
\end{tabular}

$\mathrm{CI}=$ confidence interval.

with open plafond fracture, 10 developed an infection $(42 \%)$.

For compartment syndrome risk, there were no differences between early and delayed groups for plateau fractures (early fixation: six of 42 [14\%]; delayed fixation: three of 45 [7\%]; RR $=0.47[0.12-1.75], \mathrm{p}=0.304)$ and plafond fractures (early fixation: two of 38 [5\%]; delayed fixation: three of 34 [9\%]; $\mathrm{RR}=1.67$ [0.30-9.44], $\mathrm{p}=$ 0.662). All patients requiring fasciotomy underwent surgical four-compartment release. Nine patients (10\%) with tibial plateau fracture developed compartment syndrome requiring fasciotomy (Table 3). Six patients developed compartment syndrome in the early external fixation group and three patients in the delayed external fixation group. Only one patient with compartment syndrome developed infection. Two of the six patients (33\%) in the early external fixation group developed compartment syndrome after placement of the external fixator, whereas four underwent fasciotomy and external fixation in the same operative event. Similarly, one of three patients $(33 \%)$ in the delayed external fixation group developed compartment syndrome diagnosed after external fixation had been placed. Five patients (7\%) with tibial plafond fracture developed compartment syndrome requiring fasciotomy (Table 3). One patient with compartment syndrome developed deep infection (20\%). All patients in the plafond cohort developed compartment syndrome after external fixation. The longest duration from injury to development of compartment syndrome was 33 hours (range, 16-33 hours) for tibial plafond fractures and 31 hours (range, 5-31 hours) for tibial plateau fractures.

Does delay in time to spanning external fixation of high energy tibial plateau and plafond fractures correlate with time to definitive fixation, length of hospitalization, or secondary surgeries after definitive fixation?

Tibial plateau fractures in the early external fixation group underwent definitive fixation in fewer days ( $8 \pm 6$ days) than the delayed external fixation group (11 \pm 7 days) (mean difference $=2.9[95 \% \mathrm{CI}, 0.13-5.7], \mathrm{p}=0.040)$. However, there was no difference in time to definitive fixation between the early external fixation ( $12 \pm 7$ days) and delayed external fixation (12 \pm 6 days) groups for plafond fractures (mean difference $=0.39$ [95\% CI, -2.7 to 3.4], $\mathrm{p}=0.801$ ) (Table 3). There was no difference in length of hospitalization between early external fixation and delayed external fixation for either tibial plafond (early [ $9 \pm 7$ days] versus delayed fixation $[9 \pm 6$ days] [mean difference $=0.24\{95 \%$ $\mathrm{CI},-2.9$ to $3.4 \mathrm{\}}, \mathrm{p}=0.878]$ ) or plateau fractures (early $[10 \pm 6$ days $]$ versus delayed fixation $[8 \pm 4$ days $]$ [mean difference $=1.6\{95 \% \mathrm{CI},-3.9$ to 0.7$\}$, $\mathrm{p}=0.170]$ ).

For plateau fractures, there was no difference between the early external fixation and delayed external fixation cohorts in proportion of patients requiring additional procedures or the total number of additional procedures. Secondary surgeries after tibial plateau fracture included 
Table 4. Secondary surgeries after tibial plateau fractures and tibial plafond fractures

\begin{tabular}{lc}
\hline Secondary surgery & Case numbers \\
\hline Tibial plateau ( $\mathrm{n}=87)$ & 50 \\
Total secondary surgeries & 15 \\
Removal of hardware & 8 \\
Revision for nonunion & 20 \\
Manipulation under anesthesia & 7 \\
TKA & \\
Tibial plafond ( $\mathrm{n}=72)$ & 29 \\
Total secondary surgeries & 14 \\
Removal of hardware & 11 \\
Revision for nonunion & 8 \\
Tibiotalar arthrodesis & 2 \\
Amputation & \\
\hline
\end{tabular}

manipulation under anesthesia, removal of hardware, and conversion to TKA (Table 4).

Fifty patients (57\%) who sustained a tibial plateau fracture required a secondary procedure of any kind ( 24 of 42 [57\%] patients in the early external fixation group and 26 of 45 [58\%] patients in the delayed external fixation group; adjusted relative risk $=1.0$ [95\% CI, 0.70-1.45], $\mathrm{p}=$ 1.00) (Table 3). Patients in the early external fixation group underwent a total of 46 secondary procedures $(1 \pm 2$ procedures per patient). Patients in the delayed external fixation group underwent a total of 60 secondary procedures $(1 \pm 2$ procedures per patient) (mean difference 0.24 [95\% CI, -0.63 to 1.1$], \mathrm{p}=0.586$ ]

For plafond fractures, there was no difference between the early external fixation and delayed external fixation cohorts in proportion of patients requiring additional procedures or the total number of additional procedures. Secondary surgeries after tibial plafond fracture included removal of hardware, revision for nonunion, tibiotalar arthrodesis, and below-knee amputation (Table 4). There were 34 patients $(46 \%)$ with tibial plafond fracture who required secondary procedures, not counting the definitive fixation surgery (Table 3). Twenty-one of 38 (55\%) patients in the early external fixation group and 13 of 34 $(38 \%)$ patients in the delayed external fixation group required an additional procedure (adjusted relative risk $=$ 0.69 [95\% CI, 0.41-1.16], $\mathrm{p}=0.165$ ). Patients in the early external fixation cohort underwent a total of 56 secondary procedures $(2 \pm 2$ procedures per patient), and the patients in the delayed external fixation cohort underwent a total of 29 secondary procedures $(1 \pm 1$ procedure per patient) (mean difference 0.65 [95\% CI, -1.52 to 0.23$], \mathrm{p}=0.145$ ). Both patients who underwent amputation sustained open Grade IIIB tibial plafond fractures that subsequently developed infected nonunions. The indications for amputation were patient choice. The patients had undergone several failed limb salvage procedures, and both patients wanted amputation to avoid future reconstructive surgery.

\section{Discussion}

Given the high rate of complications with immediate ORIF in treating high-energy articular lower extremity fractures, a protocol of spanning external fixation and delayed ORIF has been widely adopted. Multiple studies have demonstrated reduced infection rates with this protocol [2, 4-6, 12]. However, the question of the urgency with which the temporizing external fixation must be applied has not been addressed. In practical clinical terms, many of these highenergy C-type articular fractures will arrive at the regional trauma center in the evening. In essence, this investigation attempted to explore if these injuries need to be placed in temporizing fixators that evening or if they could be addressed in a dedicated trauma room in the morning. In the current study, we were unable to demonstrate a difference in the rate of infection, rate of compartment syndrome, length of hospitalization, or number of secondary procedures for patients whose external fixation applied within 12 hours of injury versus greater than 12 hours from injury for either tibial plateau or tibial plafond fractures. The theoretical advantage of early external fixation for high-energy lower extremity injuries is stabilization of the bone and soft tissue, thus mitigating continued soft tissue damage and subsequent complications. This study addressed a novel question and is the first to analyze the impact of the timing of the application of temporizing external fixator in the staged management of lower extremity periarticular injuries. However, the current study did not demonstrate a difference in rate of infection, secondary procedures, or rate of compartment syndrome, suggesting that this theoretical advantage either does not exist or cannot be shown with this sample.

This study has several limitations including its followup rate, retrospective design, sample size, and inclusion of multiple surgeons to treat these injuries. First, our facility is a regional trauma center covering five states, so achieving followup care through 6 months can be particularly difficult, especially in the absence of complication. This investigation only included patients with a minimum of 6 months of followup, which was achieved by $63 \%$ of the potentially eligible patients. Although this may underestimate or overestimate our complication rate, the majority of the outcomes measured (infection, compartment syndrome) can be expected to occur within 6 months, thus making this a reasonable cutoff. The inability for patients to travel many hundreds of miles for routine followup in a 
catchment this size is simply a practical and financial reality. Second, as a retrospective study our method for classifying patients into early versus delayed external fixation cohorts may be subject to some recall bias because injury records from emergency providers were used to determine the time of injury. However, this is the information that is available to the orthopaedic surgeon to base his or her decision for application of temporizing external fixation, thus making the study applicable to actual clinical practice. Third, despite a sample size that equals most of the largest in the literature, it is possible that an existing difference was simply not revealed. Also, the presence of compartment syndrome in this series is defined by performance of fasciotomy. Some fasciotomies may not have been needed, and some compartment syndromes might have been missed, but there was no suggestion of missed compartment syndrome in clinical followup. Finally, based on the retrospective design of this study and the inclusion of multiple treating physicians, it is difficult to appreciate injury factors that may have pushed a treating surgeon to decide early versus delayed spanning fixation including compromised skin and axial shortening. However, because surgeon discretion was involved, this may introduce bias, and there may be a group that benefits from early fixation that indeed received early fixation in this series. This also mimics the scenario in practice, in which multiple providers with different training and practice patterns are involved in the care of these patients.

The initial morbidity after tibial plateau and tibial plafond fractures is generally related to soft tissue complications such as infection and compartment syndrome. Egol et al. [4] initially reported a 5\% infection rate using staged management of tibial plateau fractures in a study including a wide range of fractures, many of which were lower energy patterns. More recently, Morris et al. [8] reported a $14 \%$ infection rate using spanning external fixation in a majority of plateau fracture patients. Harborview Medical Center reported a $18 \%$ overall infection rate $(8 \%$ deep infection) for high-energy tibial plateau fractures using a dual-incision technique [1]. In a recent study that predominantly used a staged protocol, Ruffolo et al. [11] reported a $24 \%$ deep infection rate for high-energy, bicondylar tibial plateau fractures. Our study shows a $6 \%$ superficial infection rate and $13 \%$ deep infection rate in a comparable patient cohort of only high-energy plateau fractures. None of the prior studies addressed time interval from injury to application of external fixation, but this series demonstrated no difference in infection rate between delayed external fixation and early external fixation.

Deep infection rates for patients undergoing staged treatment of tibial plafond fractures in the previously reported literature are $0 \%$ to $6 \%[9,12]$. Our reported $18 \%$ deep infection rate is much higher than the rates reported in the literature. However, nearly one-third of our patients sustained an open fracture, much higher than previous series, which likely contributes to the higher deep infection rate. Similarly, there was no demonstrable difference in infection rate between those externally fixed early or late.

Egol et al. reported a $19 \%$ rate of compartment syndrome using staged management for tibial plateau fractures and Morris et al. reported 7\% [4, 8]. Harborview reported $14.5 \%$ compartment syndrome in a similar population [2]. Our study showed a $10 \%$ rate of compartment syndrome treated with fasciotomies, very much in line with the existing literature, and the timing of the application of the external fixator did not correlate with the diagnosis of compartment syndrome. The reported rate of compartment syndrome in tibial plafond fractures in the literature is less than $5 \%[3,14]$. Nearly $7 \%$ of the patients in our current series were diagnosed with compartment syndrome requiring fasciotomy. This is a slight variation from previously reported rates, but given the high rate of open fracture in our series of plafonds, it may simply indicate the high-energy nature of the fractures in this series. Once again, there was no correlation between timing of temporizing fixation and diagnosis of compartment syndrome.

Previous studies have not examined time to definitive fixation, and in our plafond series, the time to definitive fixation and length of hospitalization were no different between the early and late external fixation groups. However, those tibial plateau fractures that received early external fixation had a significantly shorter time to definitive fixation. This might indicate some advantage to earlier temporizing fixation, but ultimately the delayed external fixation and early external fixation groups showed no difference in length of hospitalization, which might be expected with a shorter time to definitive fixation.

Despite using a staged treatment protocol for managing these high-energy injuries, the secondary surgery rate remained high. Aside from procedures performed for infection or compartment syndrome, over $50 \%$ of patients with a tibial plateau fracture and nearly $50 \%$ of patients with a tibial plafond fracture underwent secondary surgery. These complication rates are similar to recent studies reporting on the complications of these high-energy injuries treated with a staged protocol [8, 11, 15]. In a recent study that predominantly used a staged protocol, Ruffolo et al.'s [11] series of high-energy, bicondylar tibial plateau fractures demonstrated a $10 \%$ nonunion rate, whereas our study showed a $9 \%$ nonunion rate in a comparable patient cohort. The timing of external fixation did not appear to influence the rate of these secondary surgeries in either plateau of plafond fractures. 


\section{Conclusions}

This study was unable to demonstrate a difference in rate of infection, compartment syndrome, number of secondary procedures, or length of hospitalization for patients who underwent early external fixation as compared with delayed external fixation after high-energy tibial plateau or tibial plafond fractures. Clinically, this may influence the timing of application of provisional external fixation for high-energy lower extremity articular fractures, because urgent operative intervention has demonstrated no benefit. For trauma centers, this may impact resource use, specifically the decision whether high-energy periarticular lower extremity fractures need to be spanned on the evening of presentation or whether this procedure may wait until the morning trauma room. Given the high complication rate of these injuries and clinical relevance of this question, this may also need to be examined in a prospective manner.

Acknowledgments We thank Timothy C. Beals MD, and Florian Nickisch MD, for the inclusion of their patients in this study.

\section{References}

1. Barei DP, Nork SE, Mills WJ, Coles CP, Henley MB, Benirschke SK. Functional outcomes of severe bicondylar tibial plateau fractures treated with dual incisions and medial and lateral plates. J Bone Joint Surg Am. 2006;88:1713-1721.

2. Barei DP, Nork SE, Mills WJ, Henley MB, Benirschke SK. Complications associated with internal fixation of high-energy bicondylar tibial plateau fractures utilizing a two-incision technique. J Orthop Trauma. 2004;18:649-657.

3. Bourne RB, Rorabeck CH, Macnab J. Intra-articular fractures of the distal tibia: the pilon fracture. J Trauma Inj Infect Crit Care. 1983;23:591-596.

4. Egol KA, Tejwani NC, Capla EL, Wolinsky PL, Koval KJ. Staged management of high-energy proximal tibia fractures
(OTA types 41): the results of a prospective, standardized protocol. J Orthop Trauma. 2005;19:448-455; discussion 456.

5. Howard JL, Agel J, Barei DP, Benirschke SK, Nork SE. A prospective study evaluating incision placement and wound healing for tibial plafond fractures. J Orthop Trauma. 2008;22: 299-305; discussion 305-306.

6. Laible C, Earl-Royal E, Davidovitch R, Walsh M, Egol KA. Infection after spanning external fixation for high-energy tibial plateau fractures: is pin site-plate overlap a problem? J Orthop Trauma. 2012;26:92-97.

7. McFerran MA, Smith SW, Boulas HJ, Schwartz HS. Complications encountered in the treatment of pilon fractures. J Orthop Trauma. 1992;6:195-200.

8. Morris BJ, Unger RZ, Archer KR, Mathis SL, Perdue AM, Obremskey WT. Risk factors of infection after ORIF of bicondylar tibial plateau fractures. J Orthop Trauma. 2013;27: e196-200.

9. Patterson MJ, Cole JD. Two-staged delayed open reduction and internal fixation of severe pilon fractures. J Orthop Trauma. 1999;13:85-91.

10. Ricci WM, Gallagher B, Brandt A, Schwappach J, Tucker M, Leighton R. Is after-hours orthopaedic surgery associated with adverse outcomes? A prospective comparative study. $J$ Bone Joint Surg Am. 2009;91:2067-2072.

11. Ruffolo MR, Gettys FK, Montijo HE, Seymour RB, Karunakar MA. Complications of high-energy bicondylar tibial plateau fractures treated with dual plating through two incisions. J Orthop Trauma. 2015;29:85-90.

12. Sirkin M, Sanders R, DiPasquale T, Herscovici D. A staged protocol for soft tissue management in the treatment of complex pilon fractures. J Orthop Trauma. 2004;18:S32-38.

13. Teeny SM, Wiss DA. Open reduction and internal fixation of tibial plafond fractures. Variables contributing to poor results and complications. Clin Orthop Relat Res. 1993;292:108-117.

14. Tornetta P, Weiner L, Bergman M, Watnik N, Steuer J, Kelley M, Yang E. Pilon fractures: treatment with combined internal and external fixation. J Orthop Trauma. 1993;7:489-496.

15. Wasserstein D, Henry P, Kreder H, Paterson M, Jenkinson R. Risk factors for re-operation and mortality after the operative treatment of tibial plateau fractures in Ontario, 1996-2009. J Orthop Trauma. 2015;29:182-188.

16. Young MJ, Barrack RL. Complications of internal fixation of tibial plateau fractures. Orthop Rev. 1994;23:149-154. 